\title{
Contact dermatitis is an unrecognized problem in the construction industry: Comparison of four different assessment methods
}

\author{
Johan G. Timmerman $\mathrm{PhD}^{1}$ (D) | Dick Heederik $\mathrm{PhD}^{1}$ ｜ Ton Spee $\mathrm{PhD}^{1,2}$ \\ Frits G. van Rooy MD, PhD ${ }^{1,3}$ | Esmeralda J. M. Krop PhD ${ }^{1}$ \\ Thomas Rustemeyer MD, PhD ${ }^{4}$ | Lidwien A. M. Smit PhD ${ }^{1}$
}

1 Institute for Risk Assessment Sciences (IRAS), Utrecht University, Utrecht, The Netherlands

${ }^{2}$ Arbouw Research and Development, Harderwijk, The Netherlands

${ }^{3}$ Arbo Unie Expert Centre for Chemical Risk Management, Haarlem, The Netherlands

${ }^{4}$ Department of Dermatology, VU University Medical Centre, Amsterdam, The Netherlands

\section{Correspondence}

Lidwien A. M. Smit, Institute for Risk Assessment Sciences, Division Environmental Epidemiology, PO Box 80178, 3508 TD Utrecht, The Netherlands.

Email: I.a.smit@uu.nl

Funding information

Arbouw Research and Development,

Grant number: 11-025
Background: A high contact dermatitis symptoms prevalence has been observed in Dutch construction workers.

Methods: Contact dermatitis was diagnosed by an expert panel using questionnaire data and photographs of 751 subjects' hands. A subset was evaluated by two occupational physicians. Their diagnoses were compared to those of the expert panel.

In addition, two self-reported questionnaire-based assessment methods were compared to the expert panel evaluation. Associations between contact dermatitis and determinants were assessed using log-binomial regression analysis.

Results: Contact dermatitis prevalence was high: $61.4 \%$ (expert panel's diagnosis) and $32.9 \%$ (self-reported). Agreement between occupational physicians and the expert panel was low but increased after training. Washing hands with solvents and performing job-related tasks at home were related to contact dermatitis.

Conclusions: Contact dermatitis prevalence among construction workers is high. Recognition of contact dermatitis by occupational physicians is poor but can be improved by training. Awareness of skin disorders should be raised.

\section{KEYWORDS}

agreement, construction industry, determinants, diagnosis, occupational contact dermatitis, occupational health care, prevalence

\section{1 | INTRODUCTION}

The construction industry is an important component of worldwide economies and provides employment for millions of people. In the Netherlands, the construction industry provided 412000 full time jobs in 2013. ${ }^{1}$ Construction workers are exposed to a wide array of hazards during their work, including those of falling, ${ }^{2}$ high noise levels, ${ }^{3}$ and all sorts of potentially hazardous substances, such as (respirable) dust, ${ }^{4,5}$ fumes, ${ }^{6,7}$ solvents, $^{8}$ and allergens. ${ }^{9}$

Due to the wide range of workplace hazards, safety measures and good preventive health care are of paramount importance to ensure construction workers' health. However, the large array of possible health impairments also complicates health screening. In recent years, in the Netherlands, occupational health care in construction workers has focussed on several occupational diseases, like silicosis, ${ }^{10} \mathrm{CSE}^{8}$ and hearing problems, ${ }^{11}$ but hardly on skin diseases. As skin diseases can have a gradual and intermittent course, it can be difficult to detect these diseases at an early stage by means of periodical check-ups. ${ }^{12}$ Dutch construction workers are entitled to a periodical check-up at their occupational health service every 2 to 4 years, depending on their age. These check-ups are not obligatory and about 50\% of the construction workers actually visits the check-up. Conclusions about 
occupational disorders are based on a combination of a self-reported symptom questionnaire and a medical examination. Although selfadministered hand dermatitis symptom questionnaires have been proven to be valid in nurses ${ }^{13}$ it is known that in industrial populations, validity is questionable. ${ }^{14}$ In construction workers, doctor-diagnosis of hand dermatitis was strongly associated with filaggrin loss-of-function mutations, a well-known risk factor for dermatitis, whereas selfreported symptoms resulted in relatively weak associations. ${ }^{15}$ This result was part of an investigation in a subset of the current study population of which blood samples were available. For that subset, also the contact dermatitis prevalence was reported, which was found to be high: $56.3 \%$ of the subjects were diagnosed with at least two mild symptoms or one severe sign of contact dermatitis.

The present study has two objectives. The first objective is to compare four different assessment methods for contact dermatitis. These four methods are self-reported questionnaire items, self-reported photobased questionnaire items, evaluation by an occupational physician and evaluation by a dermatological expert team (used as reference standard). Second objective of this study is to explore associations between materials or working methods and contact dermatitis in construction workers. Results of this study may contribute to improved occupational health care and prevention of contact dermatitis in construction workers.

\section{2 | MATERIALS AND METHODS}

\section{1 | Study population}

Two approaches were used to recruit subjects. First, a "skin module," consisting of a questionnaire, and photographing of the skin of the hands of the subjects, was added to the regular check-up at eight locations of the collaborating occupational health service. This occupational health service is one of the biggest in The Netherlands and the eight locations with the most check-ups for the construction industry were selected. Second, a number of construction companies was visited during an education session on skin protection and glove use. The participating companies, which were invited via a newsletter of Arbouw, facilitated the participation of their employees after this session. In both approaches, subjects were randomly selected to obtain a representative sample of the Dutch construction industry as a whole. We consider our study population as one group as we do not have reasons to presume both groups are demographically different. In this study, construction workers are defined as those workers to whom the collective labor agreement for the construction industry applies. This means for instance that electricians, to whom the collective labor agreement for the metal industry applies, were excluded from this study. For the same reason, selfemployed workers were not included. Details of the subject recruitment, the questionnaire and methods of dermatological evaluation were described before. ${ }^{15}$ Written informed consent was obtained from all study subjects. In the current study, all subjects with complete questionnaire data and photos were included $(n=751)$. A flowchart of subject inclusion is shown in online supplemental Table SI. The study was approved by the Medical Ethical Committee of the University Medical Centre, Utrecht, the Netherlands.

\section{2 | Dermatological evaluations}

Dermatological evaluations were carried out by an expert panel consisting of a dermatologist and an occupational physician specialized in dermatological problems. They made use of questionnaire data (see online supplement SII for the items that were available for the expert panel) and assessed photographs of the subjects' hands that were made using a standardized photo lighting chamber, as described earlier. ${ }^{15}$ The experts came to a consensus diagnosis for each subject. The following possible symptoms of contact dermatitis were assessed: erythema, papules, skin scales, crusts, pigment changes and atrophy (all mild symptoms), fissures, vesicles, bullae and ulceration (severe symptoms). ${ }^{16}$ Presence of two or more mild symptoms was diagnosed as mild (or beginning) contact dermatitis, when at least one severe symptom was present, severe contact dermatitis was diagnosed. In addition, based on the questionnaire data, atopic predisposition, and relation with occupation were assessed. Also based on the questionnaire data, an assessment was made of the type of contact dermatitis (eg, irritant contact dermatitis, allergic contact dermatitis) but this was not confirmed by patch tests, and therefore qualified as "potentially irritant" contact dermatitis etc.

Additionally, to assess the ability of occupational physicians to recognize skin symptoms, a subset of 150 out of the total of 751 photos was randomly selected and randomly divided into two groups. These photos were evaluated and scored by two occupational physicians working at the occupational health service that participated in the study. They did not work at the same location and were blinded for each other's results. Both occupational physicians had many years of experience with performing the medical check-ups in the construction industry. The first group of the photograph subset was scored before the occupational physicians received a one-day refresher course in occupational dermatology by the expert panel, the second half was scored after this training. The results of the expert panel and the occupational physicians in these subgroups of the study population were compared with the diagnosis of the expert panel as a reference standard.

\section{3 | Questionnaire}

The questionnaire included items on skin symptoms, respiratory symptoms, hand hygiene, and occupational activities and exposures. Relevant questions can be found in online supplement SII. Questionnaire-items used for assessing self-reported contact dermatitis according to Jungbauer et $\mathrm{al}^{17}$ can be found in Table 1. An additional questionnaire was used, showing pictures of dermatitis of increasing severity. This pictionnaire, which was developed by the Dutch Centre for Skin and Occupation (Centrum Huid en Arbeid), was used to assess whether the use of photos in a questionnaire increases subjects' ability to report their hand skin condition. In this pictionnaire, subjects report whether they recognize the depicted dermatitis symptoms. Symptoms are depicted in three stages of increasing severity. The first stage was classified as mild contact dermatitis, the second and third stages were considered to be severe contact dermatitis, see online supplement SIII.

An overview of the different assessment methods and contact dermatitis definitions is given in Table 2 . 


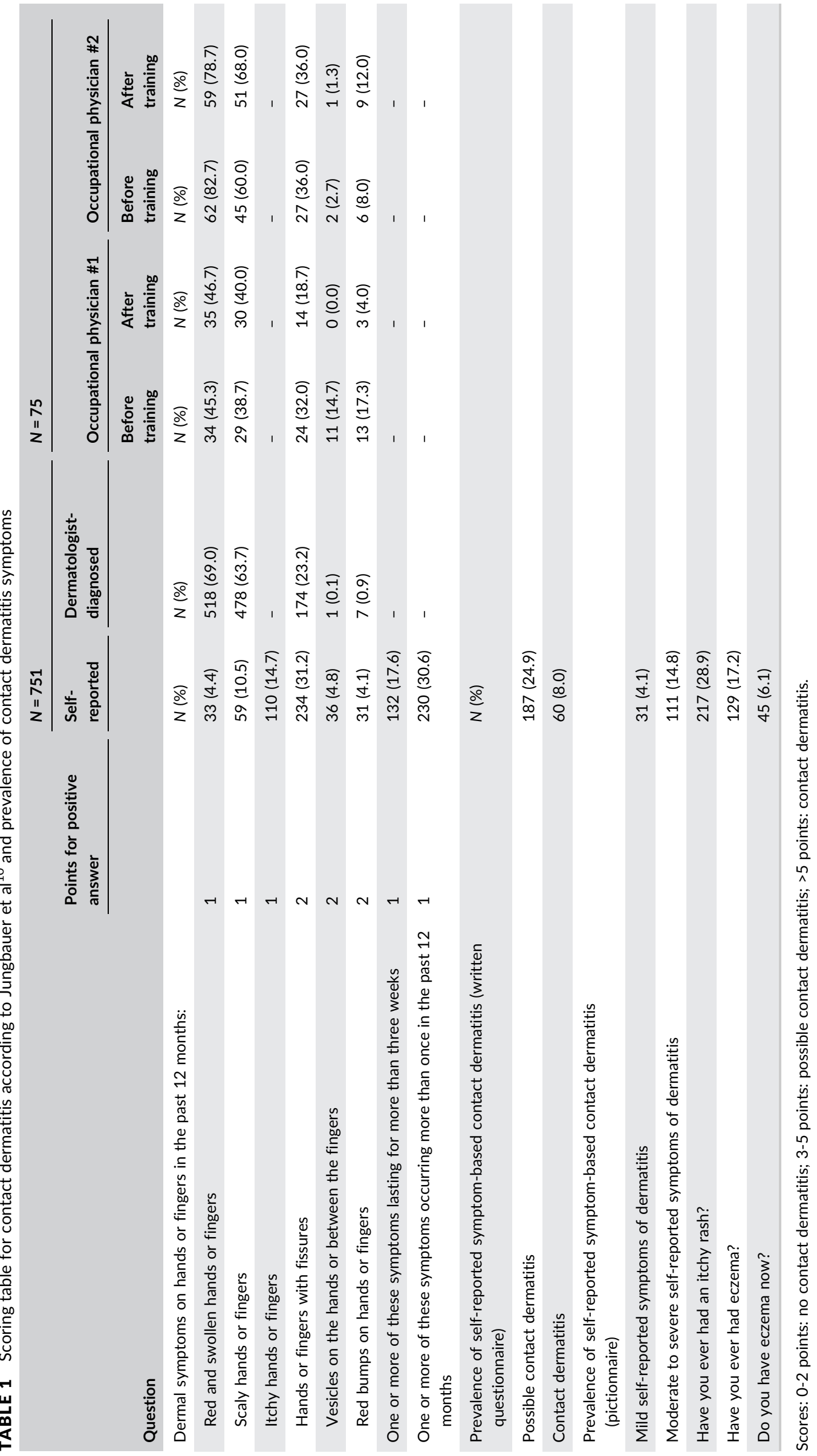




\section{4 | Data analysis}

All statistical analyses were performed using SAS 9.4 (SAS System for Windows, SAS Institute, Cary, NC). Agreement between the expert panel's diagnosis (reference) and occupational physicians' diagnoses, self-reported contact dermatitis based on the questionnaire and selfreported contact dermatitis based on the pictionnaire were calculated and presented as Cohen's kappa. For the occupational physicians' diagnoses, sensitivity, specificity, positive predictive value (PPV), and negative predictive value (NPV) were calculated.

Using log-binomial regression analysis, ${ }^{18}$ associations between contact dermatitis (mild contact dermatitis and severe contact dermatitis according to the expert panels' diagnosis were analyzed together as "contact dermatitis") and the various risk factors were presented as crude and adjusted prevalence ratios (PR) and 95\% confidence intervals (95\% $\mathrm{Cl}$ ). Job titles were categorized into four main categories: carpenters, bricklayer, painters, and other job titles. In regression analyses, painters were used as reference group as contact dermatitis prevalence was lowest in this group. PRs were adjusted for age, method of recruitment and season, where "eczema season" was defined as the 6 months in which skin symptom prevalence was found highest (December until May). ${ }^{19} \mathrm{~A}$ multiple regression model was built, based on backwards selection of variables with $P$ values $<0.2$ in univariate regression analysis. Subsequently, the variable with highest $P$-value was eliminated. This step was repeated until only variables with $P$ values $<0.05$ remained in the final model. Regularly washing hands with solvents after work was not included in the model as the $P$-value for this determinant was $>0.2$ in univariate regression analysis, but after adjustment for all variables in the final model, a positive association with contact dermatitis was found. We did not find associations of contact dermatitis with atopy, both IgE serology-based and questionnaire based. ${ }^{15}$ Therefore, atopy-related variables were not included in current analyses.

\section{3 | RESULTS}

A total of 1157 construction workers were invited in the study, of whom 860 participated (response 74.3\%) and 751 subjects had complete data on questionnaire and doctor's diagnosis.

Only three subjects $(0.4 \%)$ were female, mean age was 42.5 (standard deviation [SD]: 12.9) years (Table 3). Carpenter was the most frequently mentioned job title $(45.3 \%)$, followed by painters $(13.3 \%)$ and bricklayers (9.1\%). Other job titles were reported by $28.1 \%$ of the subjects, $4.3 \%$ did not report their job title.

\section{1 | Prevalence of contact dermatitis}

Most frequently doctor-diagnosed symptoms were redness (69.0\%), scaly skin (63.7\%), and fissures (23.2\%), whereas fissures were the most frequently self-reported symptom (31.2\%), followed by itchy hands or fingers $(14.7 \%)$ and scaly hands or fingers $(10.5 \%)$, see Table 1.

The expert panel diagnosed a total of $38.2 \%$ of all subjects with mild contact dermatitis, and another $23.2 \%$ with severe contact dermatitis, leading to a total contact dermatitis prevalence, either mild or severe, of $61.4 \%$ (Table 3). The vast majority of contact dermatitis cases were classified as occupational contact dermatitis (95.2\%; 58.5\% of the study population). In $10.0 \%$ of all subjects with contact dermatitis, an atopic predisposition was proposed by the expert panel (6.1\% of our study population).

Self-reported contact dermatitis prevalence was lower. Only $6.1 \%$ reported to currently have eczema, $17.2 \%$ reportedly ever had eczema, and $28.9 \%$ reported to ever have had an itchy rash. Symptoms leading to a scores between 2 and 5, indicating possible contact dermatitis, were reported by $24.9 \%$ of all subjects; another $8.0 \%$ scored more than 5 points, indicating contact dermatitis. This leads to a combined (either possible or definitive) self-reported symptom-based contact dermatitis prevalence of $32.9 \%$. Based on the pictionnaire, $4.1 \%$ reported mild contact dermatitis symptoms and another $14.8 \%$ reported moderate to severe contact dermatitis, yielding a total contact dermatitis prevalence of $18.9 \%$ (Table 3 ).

\subsection{Agreement and predictive values}

Agreement between the expert panel's diagnosis and the various questionnaire-derived outcomes and the predictive values of these outcomes are shown in Table 4. Cohen's kappa values were low, indicating poor agreement. Almost all subjects with self-reported contact dermatitis were diagnosed with contact dermatitis by the expert panel, resulting in a high PPV of $95 \%$. However, only half of the subjects who did not report contact dermatitis were also not diagnosed with contact dermatitis by the expert panel, yielding a NPV of $47 \%$. For severe contact dermatitis, questionnaire-derived outcomes had lower PPVs (36-43\%) but higher NPVs (79-84\%).

\section{3 | Performance of occupational physicians}

Mild contact dermatitis was diagnosed by the two occupational physicians in $8.0 \%$ and $16.0 \%$ of the subjects before the training and in $21.3 \%$ and

TABLE 2 Different assessment methods and corresponding contact dermatitis definitions used in this study

\begin{tabular}{lll} 
Assessment method & Mild/beginning contact dermatitis & \multicolumn{1}{c}{ Severe contact dermatitis } \\
\hline Expert panel's diagnosis & At least two mild symptoms & At least one severe symptom \\
Occupational physician's diagnosis & At least two mild symptoms & At least one severe symptom \\
Self-reported pictionnaire & Mild symptoms & Possible contact dermatitis \\
Self-reported questionnaire & Scores 3-5 & Contact dermatitis \\
\hline
\end{tabular}


TABLE 3 Study sample demographics and prevalence of dermatologist-diagnosed dermatitis

\begin{tabular}{|lll|}
\hline & N=751 & \\
\hline & mean & SD \\
\hline Age & 42.5 & 12.9 \\
\hline & $N$ & $(\%)$ \\
\hline Female gender & 3 & 0.4 \\
\hline Job title & & \\
\hline Carpenter & 340 & 45.3 \\
\hline Bricklayer & 68 & 9.1 \\
\hline Painter & 100 & 13.3 \\
\hline Other & 211 & 28.1 \\
\hline Contact dermatitis (dermatologists' diagnosis) & & \\
\hline Mild contact dermatitis & 287 & 38.2 \\
\hline Severe contact dermatitis & 174 & 23.2 \\
\hline Contact dermatitis with atopic predisposition & 46 & 6.1 \\
\hline Occupational contact dermatitis & 439 & 58.5 \\
\hline
\end{tabular}

$25.3 \%$ after the refresher course by the expert panel. Severe contact dermatitis was diagnosed in $32.0 \%$ and $36.0 \%$ before the training and in $18.7 \%$ and $34.7 \%$ of the subjects after the training, see Table 5.

Mutual agreement between the two occupational physicians was fair for contact dermatitis (Cohens kappa: $0.46,95 \% \mathrm{Cl}: 0.27-0.66$ ) and increased slightly after the training (0.51 [0.34-0.69]). For severe contact dermatitis, mutual agreement was moderate before the training $(0.58$ [0.38-0.77]) but decreased after the training (0.47 [0.26-0.68]). Agreement of the occupational physicians with the expert panel was lower but increased after the training: for both contact dermatitis and severe contact dermatitis. NPVs of the occupational physicians diagnoses of mild contact dermatitis increased after the training: from $41.9 \%$ to $53.3 \%$ and from $37.1 \%$ to $60.0 \%$. For severe contact dermatitis, the NPV was high and did not change by training (from $80.9 \%$ to $81.6 \%$ and from $87.8 \%$ to $85.2 \%$ ). PPVs of the occupational physicians' diagnoses of both contact dermatitis (either mild or severe) and severe contact dermatitis increased after the training.

\section{4 | Determinants}

Crude and adjusted PRs for the various factors possibly associated with contact dermatitis (either mild or severe, expert panel's diagnosis) are shown in Table 6. Several determinants were significantly associated with contact dermatitis in the multiple regression model: recruitment at a construction company (PR 1.25, 95\% Cl: 1.09-1.43); use of hand cream (PR 1.21, 95\% Cl: 1.10-1.34); performing jobrelated activities at home for more than $4 \mathrm{hr}$ a week (PR 1.14, 95\% Cl: 1.04-1.26); age (PR per 10 years increase: $1.04,95 \% \mathrm{Cl}: 1.01-1.09) ;$ job title (carpenters: PR 1.92, 95\% Cl: 1.45-2.54; bricklayers: PR 2.05, 95\% $\mathrm{Cl}$ : $1.50-2.81$ and other job titles: PR $1.93,95 \% \mathrm{Cl}: 1.45-2.58$, all compared to painters); and regularly washing the hands with solvents (PR 1.17, 95\% Cl: 1.03-1.34. Generally, the magnitude of associations decreased after adjustment for covariates, except for regularly washing the hands with solvents, which was not associated with contact dermatitis in univariate analysis.

Reporting "cleaning the hands after work is not easy" was also significant after adjustment for all variables in the full model (PR 1.13, $95 \% \mathrm{Cl}: 1.04-1.24)$. However, this variable and "reporting very dirty hands after work," were not included in the stepwise variable selection as subjects with self-reported skin symptoms may be more aware of hand contamination, or may have more problems to clean their hands. Subjects reporting dermal symptoms indeed stated their hands to be dirty and/or difficult to clean more often than subjects without selfreported dermal symptoms, independent from the expert panel's diagnosis (data not shown).

Sensitivity analyses with mild contact dermatitis and severe contact dermatitis as health endpoint showed a stronger effect of job title for severe contact dermatitis (PR $>3$ for all job titles compared to painters). Analyses within job titles did not identify additional occupational determinants of contact dermatitis (shown in online supplements SIV and SV).

TABLE 4 Comparison of self-reported outcomes with the expert panel's diagnoses

\begin{tabular}{|c|c|c|c|c|c|}
\hline & $\begin{array}{l}\text { Sensitivity } \\
\text { (\%) }\end{array}$ & $\begin{array}{l}\text { Specificity } \\
\text { (\%) }\end{array}$ & $\begin{array}{l}\text { PPV } \\
\text { (\%) }\end{array}$ & $\begin{array}{l}\text { NPV } \\
(\%)\end{array}$ & $\begin{array}{l}\text { Cohen's kappa }(95 \% \\
\text { Cl) }\end{array}$ \\
\hline \multicolumn{6}{|c|}{$\begin{array}{l}\text { Compared to contact dermatitis (mild and/or severe; doctor- } \\
\text { diagnosed) }\end{array}$} \\
\hline Possible contact dermatitis (questionnaire-derived) & 42 & 82 & 79 & 47 & $0.21(0.15-0.27)$ \\
\hline Contact dermatitis (questionnaire-derived) & 12 & 99 & 95 & 41 & $0.09(0.06-0.11)$ \\
\hline Severe hand eczema (pictionnaire-derived) & 20 & 90 & 76 & 41 & $0.08(0.03-0.12)$ \\
\hline \multicolumn{6}{|l|}{ Compared to severe contact dermatitis (doctor-diagnosed) } \\
\hline Contact dermatitis (questionnaire-derived) & 15 & 94 & 43 & 78 & $0.12(0.04-0.19)$ \\
\hline Fissures (questionnaire derived) & 52 & 75 & 38 & 84 & $0.24(0.16-0.31)$ \\
\hline
\end{tabular}


TABLE 5 Comparison of occupational physicians' outcomes with the expert panel's diagnoses

\begin{tabular}{|c|c|c|}
\hline & Before training & After training \\
\hline \multicolumn{3}{|l|}{ Prevalence } \\
\hline \multicolumn{3}{|l|}{ Occupational physician \#1 } \\
\hline Severe contact dermatitis & $32.0 \%$ & $18.7 \%$ \\
\hline \multicolumn{3}{|l|}{ Occupational physician \#2 } \\
\hline Severe contact dermatitis & $36.0 \%$ & $34.7 \%$ \\
\hline \multicolumn{3}{|l|}{ Reference: expert panel } \\
\hline Mild contact dermatitis & $44.0 \%$ & $40.0 \%$ \\
\hline Severe contact dermatitis & $24.0 \%$ & $26.7 \%$ \\
\hline Severe contact dermatitis & $0.58(0.38-0.77)$ & $0.47(0.26-0.68)$ \\
\hline \multicolumn{3}{|l|}{ Agreement with expert panel } \\
\hline \multicolumn{3}{|l|}{ Occupational physician \#1 } \\
\hline Contact dermatitis (either mild or severe) & $0.23(0.04-0.42)$ & $0.45(0.28-0.62)$ \\
\hline Severe contact dermatitis & $0.40(0.18-0.63)$ & $0.55(0.33-0.77)$ \\
\hline \multicolumn{3}{|l|}{ Occupational physician \#2 } \\
\hline Contact dermatitis (either mild or severe) & $0.12(-0.10-0.33)$ & $0.46(0.25-0.66)$ \\
\hline Severe contact dermatitis & $0.15(-0.07-0.38)$ & $0.25(0.03-0.48)$ \\
\hline \multicolumn{3}{|l|}{ Negative predictive value } \\
\hline Severe contact dermatitis & $80.9 \%$ & $81.6 \%$ \\
\hline \multicolumn{3}{|l|}{ Positive predictive value } \\
\hline \multicolumn{3}{|l|}{ Occupational physician \#1 } \\
\hline Contact dermatitis (either mild or severe) & $83.3 \%$ & $96.7 \%$ \\
\hline Severe contact dermatitis & $50.0 \%$ & $78.6 \%$ \\
\hline \multicolumn{3}{|l|}{ Occupational physician \#2 } \\
\hline Contact dermatitis (either mild or severe) & $74.4 \%$ & $84.4 \%$ \\
\hline Severe contact dermatitis & $33.3 \%$ & $42.3 \%$ \\
\hline
\end{tabular}

\section{4 | DISCUSSION}

In this study, a high prevalence of both mild (38\%) and severe contact dermatitis (an additional 23\%) was found in Dutch construction workers. Agreement of the expert panel's diagnosis (the reference standard in our study) with self-reported questionnaire items on contact dermatitis and with occupational physicians' diagnoses was low. Main occupational determinant was job title: painters had an approximately 2-fold lower prevalence of contact dermatitis than workers with other job titles. Regularly washing the hands with solvents and performing work-related tasks at home for more than $4 \mathrm{~h}$ a week were associated with a modestly increased risk of contact dermatitis.

Recently, we reported a high prevalence of self-reported skin symptoms ${ }^{19}$ and self-reported contact dermatitis. ${ }^{20}$ In earlier analyses in a subset of the current study population, also a high prevalence of doctor-diagnosed contact dermatitis was reported. ${ }^{15}$ This high contact dermatitis prevalence (mild contact dermatitis: $34.0 \%$, severe contact dermatitis: $24.3 \%$ ) was confirmed by the results in the full study population presented in the current report (mild contact dermatitis: $38.3 \%$, severe contact dermatitis: $23.2 \%$ ). Distribution of job titles in our 
TABLE 6 Factors associated with contact dermatitis in the Dutch construction industry

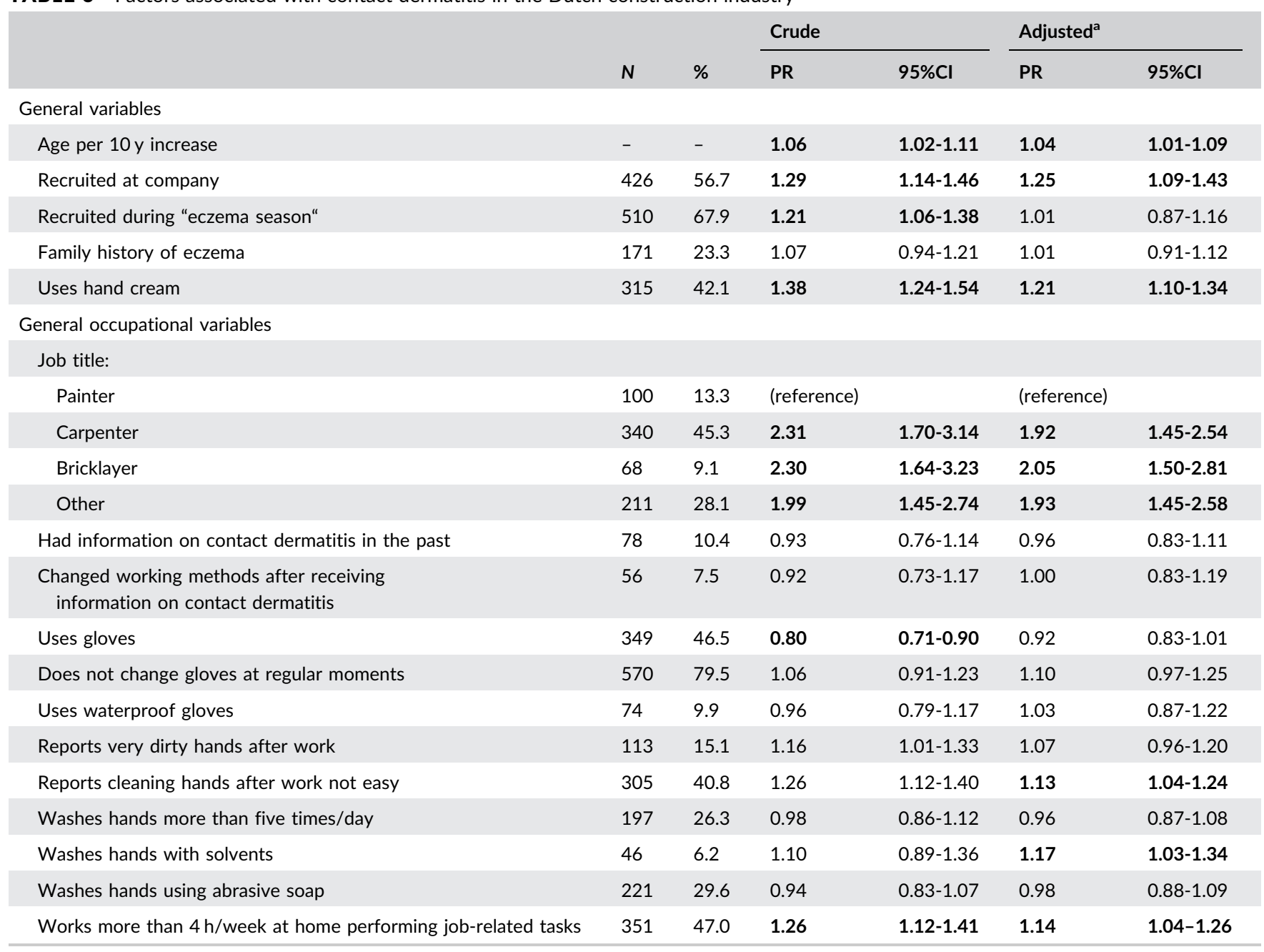

PR: prevalence ratio, $95 \% \mathrm{Cl}$ : 95\% confidence interval. Bold values signify $P$-value $<0.05$.

${ }^{a}$ All variables are shown adjusted for the following variables: age, method of recruitment, eczema season, hand cream use, job title, and performing jobrelated task at home for more than $4 \mathrm{~h}$ a week.

study sample was comparable to the Dutch construction industry as a whole, for details about subject selection see Timmerman et al. ${ }^{15}$

In 1984, the last time the dermatologist-diagnosed prevalence of contact dermatitis in Dutch construction workers was reported, a prevalence of $7.8 \%$ was found ${ }^{21}$ after examination of about 1700 construction workers. It is uncertain whether the much higher prevalence in the present study is due to a more rigorous diagnosis, or due to changes in occupational exposures that may have caused a strong increase in hand dermatitis over time.

The expert panel diagnosed contact dermatitis more often than reported by workers, either based on the questionnaire (possible contact dermatitis: $24.9 \%$, contact dermatitis: $8.0 \%$ ) or the pictionnaire (contact dermatitis: $4.1 \%$, moderate to severe contact dermatitis: 14.8\%). Mild symptoms (red skin, scaly skin) were often reported by the expert panel but not by the construction workers $(69.0 \%$ and $63.7 \%$ as recorded by the expert panel compared to $4.4 \%$ and $10.5 \%$ selfreported). The fact that construction workers did not report mild symptoms may well explain why the score of self-reported symptoms often stays below three points (the threshold score for "possible eczema") even if they report to have severe symptoms like fissures. Construction workers may not recognize mild symptoms, and only start reporting symptoms when their contact dermatitis has become severe: fissures were reported most frequently by construction workers, which was also seen in earlier studies. ${ }^{19,20}$ As the questionnaire asked for symptoms over the last 12 months and the expert panel judged a momentary picture of the hands, doctor's diagnosis-based prevalence would be expected to be lower than the self-reported prevalence, suggesting that the true 1-year prevalence is even higher than observed. In future research, it may be useful to also assess the self-reported, point prevalence to compare this with the doctors' diagnosis.

The questionnaire is used in occupational health care by occupational physicians to screen construction workers for contact dermatitis. However, this questionnaire was developed for and validated in nurses, ${ }^{13}$ and appears to be less useful in industrial populations, ${ }^{14,15}$ possibly because these workers perceive skin changes differently than nurses do. In our population, the self-reported questionnaire correctly predicted a diagnosis of mild 
contact dermatitis in $79 \%$ of the symptomatic subjects, but only $47 \%$ of the negative self-reports were correct. Interestingly, the self-reported question on fissures alone performed as good as the complete questionnaire in predicting mild contact dermatitis (PPV: $83 \%$, NPV: 48\%), but for severe contact dermatitis (PPV: $38 \%$ ) the PPV of self-reported fissures was lower than the PPV of self-reported contact dermatitis (43\%) whereas the NPVs were comparable ( $84 \%$ and $78 \%$, respectively).

Both before and after the refresher course, contact dermatitis prevalence as reported by the occupational physicians was lower than the prevalence reported by the expert panel for mild contact dermatitis but higher for severe contact dermatitis. Agreement, PPV and NPV generally increased after the refresher course. This implicates the usefulness of a course on dermatology for occupational physicians, increasing their ability to diagnose (early) signs of contact dermatitis correctly although they still underdiagnosed mild contact dermatitis $(21.3 \%$ and $25.3 \%$ vs expert panel: 38.2\%). The two occupational physicians acknowledged that construction workers were almost never referred to their general practitioner or a dermatologist for their skin problems. Thus, in regular occupational health care practice, contact dermatitis symptoms remain untreated. As construction workers themselves hardly report mild symptoms like redness and scaly skin, they will not report symptoms before they develop fissures, which is a symptom of severe contact dermatitis. To detect contact dermatitis in an early, mild state, recognition of a red, and scaly skin by the occupational physician is of importance. As many construction workers do have a red and scaly skin, these visible symptoms of early contact dermatitis may however be overlooked because this may be regarded normal for a construction worker.

The large variability between self-reported diagnoses, occupational physician's diagnoses, and the expert panel's diagnoses indicates that in occupational health care, physicians should not only be careful in relying on self-reported contact dermatitis symptoms but also should be trained in recognizing (early) contact dermatitis symptoms, in order to effectively reduce the burden of contact dermatitis in the construction industry.

In our study, photographs of the hands taken under standardized conditions were used by the expert panel as well as the occupational physicians to diagnose contact dermatitis. The use of physical examinations would be much more expensive and time-consuming, and would not fit in the routine check-up infrastructure. Moreover, according to the expert panel, the used method is as reliable as a physical examination. We did not perform patch tests to confirm allergic contact dermatitis, although the answers given to the questionnaire item "are you hypersensitive ("allergic") to certain substances?" can give a clue to the type of contact dermatitis. In general, when skin allergy or allergen exposure were not reported in the questionnaire, subjects were diagnosed with potentially irritant contact dermatitis.

A limited number of (potential) factors appeared statistically significantly associated with a contact dermatitis diagnosis. The present study aimed to evaluate the occurrence of contact dermatitis in the construction industry as a whole. However, among construction workers, there is considerable heterogeneity in terms of type and intensity of materials and products used, and the manner in which they are used. A questionnaire is a rather crude approach to assess relevant occupational exposures, leading to misclassification and underestimation of associations. Moreover, the majority of cases was diagnosed with a dry, hyperkeratotic dermatitis without additional clinical disorders and therefore potentially had irritant contact dermatitis, which can be caused by multiple non-specific exposures. In studies of specific allergic contact dermatitis, the exposure of interest can be targeted by more specific questions or exposure measurements, but this was not the purpose of the current study. We adjusted for job title because contact dermatitis prevalence was lower among painters compared to other job titles and because several determinants were expected to be associated with particular job titles. Stratification for job title, however, did not show job-title specific risk factors. The positive associations with age, washing the hands with a solvent after work and working at home for more than $4 \mathrm{~h}$ a week performing job-related tasks suggest that cumulative exposure to mildly irritant substances is a risk factor for contact dermatitis in the construction industry but interpretation is limited by the cross-sectional study design. Evidence from our previous longitudinal analysis of check-up records supported a protective effect of glove use on skin symptoms. ${ }^{19}$ The weak protective effect of glove use in the current study is in line with that result but in contrast with our earlier cross-sectional study, ${ }^{20}$ in which we observed a positive association between dermatitis and both hand cream use and glove use. In that study, we argued that those positive effects were the result of reverse causation. In the current study, this putative effect is again observed for hand cream use.

Hand cream was reported to be used by only $42.1 \%$ of the subjects, and only $18.6 \%$ reported daily hand cream use (data not shown). This may explain the high prevalence of red and scaly skin as reported by the expert panel. The expert panel remarked in $10 \%$ of subjects with contact dermatitis that hands were badly cared for, which had led to dirt inside the skin pores and/or a dry and mildly scaling skin. As a dry skin is more prone to be damaged, permeation of irritants as well as allergens into the skin is more likely to happen than with an intact skin.

Given the high prevalence of contact dermatitis amongst construction workers and the few occupational determinants identified, we decided not to develop a predictive tool but to advocate specific attention of the occupational physician to contact dermatitis in all construction workers visiting a medical check-up, especially when they report fissures.

\section{5 | CONCLUSIONS}

The prevalence of contact dermatitis amongst Dutch construction workers is high, but not sufficiently recognized by the construction workers themselves and by occupational physicians. Predictive values of self-reported questionnaires and the diagnoses of two occupational physicians were low, compared to the diagnosis of a dermatological expert panel. Protection against relatively mild irritants and good skin care to ensure a vital skin are recommended for construction workers 
to reduce the high prevalence of mild contact dermatitis and prevent it from worsening to severe contact dermatitis. Better awareness of the problem of contact dermatitis among construction workers, employers, and occupational physicians is needed to ensure lower prevalence and earlier and better diagnosis of contact dermatitis in the construction industry. Raising awareness might be done by better education of construction workers so they can recognize irritants, know how to prevent dermal exposure and know how to use hand cream to keep their skin in a healthy condition. In addition, occupational physicians should receive dermatological training to help them detect early signs of contact dermatitis on construction workers' hands.

\section{AUTHORS' CONTRIBUTIONS}

All authors were involved in the conception and design of the study, and participated in the interpretation of the data. JGT collected data during construction site visits. JGT and LAMS conducted the statistical analysis and drafted the manuscript. DH, TS, FGvR, EJMK, and TR provided comments on the manuscript and approved the submitted version.

\section{ACKNOWLEDGMENTS}

The authors thank Henny Bastiaans, Petra Beurskens, and Ardi Brouwer (Arbo Unie) for coordinating field work at the occupational health services; Tamara Onos for coordinating and supporting field work at the construction companies; Hans Bouman, Hans Clemenkowff, Mariska Droog, Tamara Onos, and Jan Snijder for giving the presentations during the educational sessions at the construction companies; Saskia Martens for supporting the field work and data processing and Daan Heynsdijk and Paul Vredebregt for assessing the photographs. We also thank the Centre for Skin and Occupation (Centrum Huid en Arbeid) for using their pictionnaire.

\section{FUNDING}

The study was financially supported by Arbouw. Grant sponsor: Research and Development Arbouw; Grant number: 11-025.

\section{ETHICS APPROVAL AND INFORMED CONSENT}

The study was performed at the Institute for Risk Assessment Sciences (IRAS), Utrecht University, The Netherlands. The study was approved by the Medical Ethical Committee of the University Medical Centre, Utrecht, The Netherlands. Written informed consent was obtained.

\section{DISCLOSURE (AUTHORS)}

The authors report no conflicts of interest. The funder had no role in study design, data analysis, or decision to publish the study, and the co-author from Arbouw was not involved in decisions about funding.

\section{DISCLOSURE BY AJIM EDITOR OF RECORD}

Steven Markowitz declares that he has no conflict of interest in the review and publication decision regarding this article.

\section{DISCLAIMER}

None.

\section{ORCID}

Johan G. Timmerman (iD http://orcid.org/0000-0001-5720-2226

\section{REFERENCES}

1. Jansen FJ. Bouw in beeld 2013-2014 [Internet]. Amsterdam: Economisch Instituut voor de Bouw; c2014 [cited 20157 April] http://www.eib.nl/pdf/bouw_in_beeld_2013-2014.pdf

2. Dong XS, Choi SD, Borchardt JG, Wang X, Largay JA. Fatal falls from roofs among U.S. construction workers. J Safety Res. 2013;44:17-24.

3. Tak S, Calvert GM. Hearing difficulty attributable to employment by industry and occupation: an analysis of the national health interview surveyUnited States, 1997 to 2003. J Occup Environ Med. 2008;50:46-56.

4. Linch KD. Respirable concrete dust-silicosis hazard in the construction industry. Appl Occup Environ Hyg. 2002;17:209-221.

5. van Deurssen E, Pronk A, Spaan S, Goede H, Tielemans E, Heederik D, Meijster T. Quartz and respirable dust in the dutch construction industry: a baseline exposure assessment as part of a multidimensional intervention approach. Ann Occup Hyg. 2014;58:724-738.

6. Antonini JM, Lewis AB, Roberts JR, Whaley DA. Pulmonary effects of welding fumes: review of worker and experimental animal studies. Am $J$ Ind Med. 2003;43:350-360.

7. Jarvholm B, Silverman D. Lung cancer in heavy equipment operators and truck drivers with diesel exhaust exposure in the construction industry. Occup Environ Med. 2003;60:516-520.

8. Spee T, van Valen E, van Duivenbooden C, van der Laan G. A screening programme on chronic solvent-induced encephalopathy among dutch painters. Neurotoxicology. 2012;33:727-733.

9. Carino M, Romita P, Foti C. Allergy-related disorders in the construction industry. ISRN Prev Med. 2013;2013:864679.

10. Suarthana E, Moons KG, Heederik D, Meijer E. A simple diagnostic model for ruling out pneumoconiosis among construction workers. Occup Environ Med. 2007;64:595-601.

11. Leensen MC, Dreschler WA. The applicability of a speech-in-noise screening test in occupational hearing conservation. Int J Audiol. 2013;52:455-465.

12. Diepgen TL, Coenraads PJ. The epidemiology of occupational contact dermatitis. Int Arch Occup Environ Health. 1999;72:496-506.

13. Smit HA, Coenraads PJ, Lavrijsen AP, Nater JP. Evaluation of a selfadministered questionnaire on hand dermatitis. Contact Dermatitis. 1992;26:11-16.

14. Vermeulen R, Kromhout H, Bruynzeel DP, de Boer EM. Ascertainment of hand dermatitis using a symptom-based questionnaire; applicability in an industrial population. Contact Dermatitis. 2000;42:202-206.

15. Timmerman JG, Heederik D, Spee T, et al. Contact dermatitis in the construction industry: the role of filaggrin loss-of-function mutations. Br J Dermatol. 2016;174:348-355.

16. Jansen LH. 1975. Huid- en geslachtsziekten. een handboek voor de praktijk van huis- en huidarts [Skin diseases and venereology: a practical handbook for general practitioners and dermatologists]. Utrecht: Scheltema \& Holkema. 
17. Jungbauer $F H$, Piebenga WP, ten Berge EE, et al. NVAB-richtlijn: Preventie Contacteczeem (NVAB guideline: prevention of Contact Dermatitis) [Internet]; c2006 [cited 20157 april]. Available from: https://www.nvab-online.nl/sites/default/files/bestandenwebpaginas/Contacteczeem\%20RL.pdf

18. Deddens JA, Petersen MR. Approaches for estimating prevalence ratios. Occup Environ Med. 2008;65:481.

19. Timmerman JG, Heederik D, Spee T, Smit LA. Skin symptoms in the construction industry: occurrence and determinants. Am J Ind Med. 2014a;57:660-668.

20. Timmerman JG, Zilaout H, Heederik D, Spee T, Smit LA. Validation of a questionnaire on hand hygiene in the construction industry. Ann Occup Hyg. 2014b;58:1046-1056.
21. Coenraads PJ, Nater JP, Jansen HA, Lantinga H. Prevalence of eczema and other dermatoses of the hands and forearms in construction workers in the Netherlands. Clin Exp Dermatol. 1984;9:149-158.

How to cite this article: Timmerman JG, Heederik D, Spee T, et al. Contact dermatitis is an unrecognized problem in the construction industry: Comparison of four different assessment methods. Am J Ind Med. 2017;60:879-888. https://doi.org/10.1002/ajim.22742 